\title{
DFT study on nonlinear optical properties of lithium-doped corannulene
}

\author{
JIANG YaJun ${ }^{1}$, LIU ZiZhong ${ }^{1 *}$, LIU HongXia ${ }^{1}$, CUI WenYing ${ }^{1}$, WANG Na ${ }^{1}$, \\ LIU DongSheng ${ }^{2} \&$ GE XiangWei ${ }^{2}$ \\ ${ }^{1}$ Inner Mongolia Key Laboratory of Green Catalysis, Chemistry and Environment Science College, Inner Mongolia Normal University, Hohhot \\ 010022, China; \\ ${ }^{2}$ Computer and Information Engineering College, Inner Mongolia Normal University, Hohhot 010022, China
}

Received April 18, 2012; accepted June 24, 2012; published online August 23, 2012

\begin{abstract}
The effects of lithium doping on the nonlinear optical properties of new electrodes (lithium-doped corannulene) were investigated in detail. Nine dynamically stable geometries of $\mathrm{Li}_{n}-\mathrm{C}_{20} \mathrm{H}_{10}(n=1,2)$ are predicted by B3LYP/6-31G(d,p). Among these nine structures, the largest first static hyperpolarizability $\left(\beta_{0}\right)$ is computed to be 15314 au, which is dramatically larger than the $\beta_{0}$ value of 74 au for $\mathrm{C}_{20} \mathrm{H}_{10}$, indicating that Li doping plays an important role in elevating the first hyperpolarizability of corannulene.
\end{abstract}

corannulene $\left(\mathrm{C}_{20} \mathrm{H}_{10}\right)$, lithium doped, nonlinear optical properties, first hyperpolarizability, DFT

Citation: Jiang Y J, Liu Z Z, Liu H X, et al. DFT study on nonlinear optical properties of lithium-doped corannulene. Chin Sci Bull, 2012, 57: 4448-4452, doi: $10.1007 / \mathrm{s} 11434-012-5437-\mathrm{Z}$

The extensive number of works that have been performed over the past two decades to investigate the nonlinear optical (NLO) properties of novel NLO materials [1-7] have been devoted to discovering the important/key influencing factors that can lead to dramatic increases in the first hyperpolarizability [8]. The strategies used mainly focused on utilizing molecules that contain extended $\pi$-electron systems [9] or that can be characterized as planar donor- $\pi$-conjugated bridge-acceptor (D- $\pi$-A) types $[10,11]$ or that contain a twisted $\pi$-electron system [12]. Incorporation of alkali metals into the organic compounds provides an alternative, efficient approach to elevate the first hyperpolarizability [13-18]. A number of fascinating NLO materials with Lidoped complexes have recently been reported [19-26]. These Li-doped complexes have shown a significantly large NLO response, and the valence electrons of the $\mathrm{Li}$ atoms play a crucial role in elevating the NLO value of these compounds. Based on these reports, we chose corannulene as a model with which to design novel Li-doped NLO mate-

*Corresponding author (email: zizhliu@yahoo.com.cn) rials with a desirably large NLO value.

The first reported synthesis of corannulene $\left(\mathrm{C}_{20} \mathrm{H}_{10}\right)$ was published by Barth and Lawton [27] in 1966, with this molecule showing aromatic character [28] and stability at high temperatures [29]. Corannulene can be thought of as the upper third of a $\mathrm{C}_{60}$ molecule with the valences of the outermost atoms saturated by $\mathrm{H}$ atoms. The molecule resembles a shallow bowl with $\mathrm{C}_{5 \mathrm{v}}$ symmetry (Figure 1) and the six-membered rings at the periphery lie significantly out of the plane. $\mathrm{C}_{20} \mathrm{H}_{10}$ exhibits a number of interesting properties [30,31] and its complexes with ions or atoms, such as alkaline cations or transition metal atoms [32-35], have been studied both experimentally and theoretically. Following the discussion above, we investigated corannulene molecules with Li doping for the design of novel NLO materials.

In the current work, to investigate the effect of Li doping on the NLO properties of corannulene, we predict the structural and electronic properties of $\mathrm{Li}_{n}-\mathrm{C}_{20} \mathrm{H}_{10}(n=1,2)$ at the atomic level. It is found that the large hyperpolarizabilities of $\mathrm{Li}_{n}-\mathrm{C}_{20} \mathrm{H}_{10}(n=1,2)$ strongly depend upon the concentration and position of the $\mathrm{Li}$ atoms. 


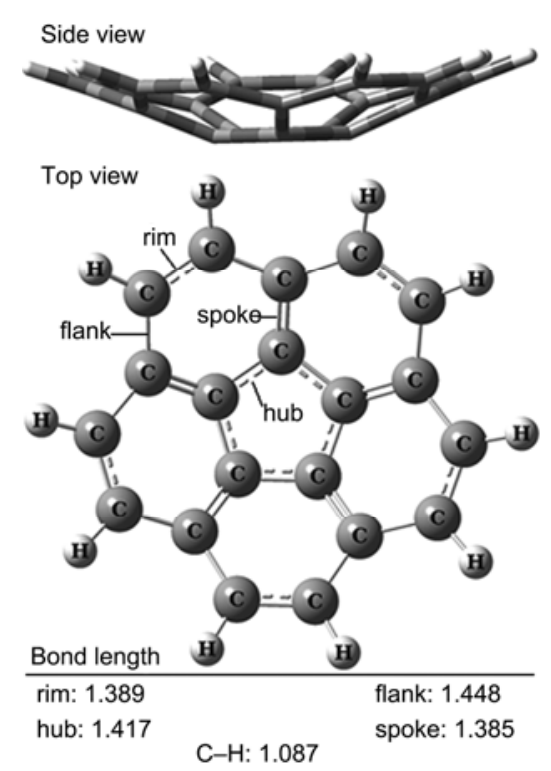

Figure 1 Optimized structure of corannulene ( $\mathrm{C}_{5 \mathrm{v}}$ symmetry). There are four types of C-C bonds: hub, spoke, flank, and rim (bond lengths in $\AA$ ).

\section{Theoretical method and computational details}

All calculations were performed using the Gaussian 03 [36] package and all structures were optimized using Becke's three-parameter hybrid functional combined with the Lee, Yang, and Parr (LYP) correlation functional (B3LYP). The calculated Hessian matrices show that all optimized geometries are local minima with no imaginary frequencies, thus indicating they are all dynamically stable. The first hyperpolarizabilities were evaluated using the finite field approach at the B3LYP level. The $6-31 \mathrm{G}(\mathrm{d}, \mathrm{p})$ basis set was employed for all calculations. The total energy of a molecular system in the presence of a homogeneous electric field can be expressed as

$$
E=E^{(0)}-\mu_{1} F_{1}-\frac{1}{2} \alpha_{i j} F_{i} F_{j}-\frac{1}{6} \beta_{i j k} F_{i} F_{j} F_{k}-\frac{1}{24} \gamma_{i j k} F_{i} F_{j} F_{k} F_{l}-\ldots
$$

where $E^{(0)}$ is the energy of the molecule in the absence of an electronic field, $\mu$ is the component of the dipole moment vector, $\alpha$ is the linear polarizability tensor, and $\beta$ and $\gamma$ are the first and second hyperpolarizability tensors, respectively. For a molecule, the average dipole moment $\left(\mu_{0}\right)$ and polarizability $\left(\alpha_{0}\right)$ are defined as follows:

$$
\begin{aligned}
& \mu_{0}=\left(\mu_{x}^{2}+\mu_{y}^{2}+\mu_{z}^{2}\right)^{1 / 2}, \\
& \alpha_{0}=\frac{1}{3}\left(\alpha_{x x}+\alpha_{y y}+\alpha_{z z}\right) .
\end{aligned}
$$

The first hyperpolarizability is defined as

$$
\beta_{0}=\left(\beta_{x}^{2}+\beta_{y}^{2}+\beta_{z}^{2}\right)^{1 / 2},
$$

where

$$
\beta_{i}=\frac{3}{5}\left(\beta_{i i i}+\beta_{i j j}+\beta_{i k k}\right), i, j, k=x, y, z
$$

\section{Results and discussion}

\subsection{Equilibrium geometries}

The bowl-shaped structure of corannulene $\left(\mathrm{C}_{20} \mathrm{H}_{10}\right)$ is well known, and we have adopted similar structural parameters to those reported in previous theoretical and experimental work [37]. The optimized structures and corresponding geometrical parameters of corannulene are shown in Figure 1. Corannulene's unique bowl shape offers a variety of binding possibilities for lithium atoms, including binding to either the concave or convex surfaces of the molecule. In this step, various configurations of $\mathrm{Li}$ doping were considered. Figure 2 shows the optimized structures of $\mathrm{Li}_{n}-\mathrm{C}_{20} \mathrm{H}_{10}(n=1$, 2). The corresponding distances between $\mathrm{Li}$ and $\mathrm{C}$ atoms (labeled $\mathrm{C} 1$ to $\mathrm{C} 6$ in Figure 2) are listed in Table 1. The given geometries of $\mathrm{Li}_{n}-\mathrm{C}_{20} \mathrm{H}_{10}(n=1,2)$ are all in $\mathrm{C}_{1}$ symmetry.

For doped structures with one Li, two different structures (1a and 1b, Figure 2) are obtained. The binding energy and NBO charge on the Li atom are listed in Table 1. The calculations show that the $\mathrm{Li}$ atom can bind to the convex or concave side of the six-membered ring, as shown in 1a and $\mathbf{1 b}$, respectively. The $\mathrm{C}-\mathrm{Li}$ distances listed in Table 1 indicate that the location of the $\mathrm{Li}$ atom is close to the center of $\mathbf{a}$ six-membered ring. The binding energies of $\mathbf{1 a}$ and $\mathbf{1 b}$ are -69.7 and $-74.1 \mathrm{~kJ} / \mathrm{mol}$, respectively, which is in good agreement with the results of Zhang et al. [31]. The NBO charges on the $\mathrm{Li}$ atoms of $\mathbf{1 a}$ and $\mathbf{1 b}$ are 0.918 (e) and 0.942 (e), respectively, indicating charge transfer from Li to corannulene.

Turning our attention to the doped geometries with two $\mathrm{Li}$ atoms, it can be seen that the two Li atoms can be located either at the concave or at the convex side. From a search of the possible isomers that such a system might adopt, we present seven different structures (2a-2g in Figure 2) of $\mathrm{Li}_{2}-\mathrm{C}_{20} \mathrm{H}_{10}$ with the two $\mathrm{Li}$ atoms located on the same side (either convex or concave) or at opposite sides of corannulene. Table 1 lists the computed binding energies and average NBO charges on the Li atoms. The structures $\mathbf{2 a}$ and $\mathbf{2 b}$ have two Li atoms sitting on the convex side of the corannulene molecule. The binding energies of these structures are -162.0 and $-163.8 \mathrm{~kJ} / \mathrm{mol}$ for $\mathbf{2 a}$ and $\mathbf{2 b}$, respectively. $\mathbf{2 c}$ and $\mathbf{2 d}$ have two Li atoms locating on the concave side of the corannulene molecule. The binding energies of $\mathbf{2 c}$ and $\mathbf{2 d}$ are -139.3 and $-152.2 \mathrm{~kJ} / \mathrm{mol}$, respectively, both of which are higher in energy than $\mathbf{2 a}$ or $\mathbf{2 b}$ (on the convex side). The structures $\mathbf{2 e}, \mathbf{2 f}$, and $\mathbf{2 g}$ have the two Li atoms adsorbed on the two opposing sides of the corannulene. The binding energies for these structures are -169.4 (2e), -178.2 


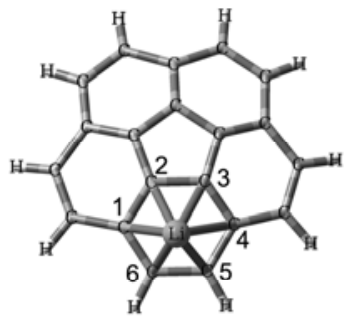

1a

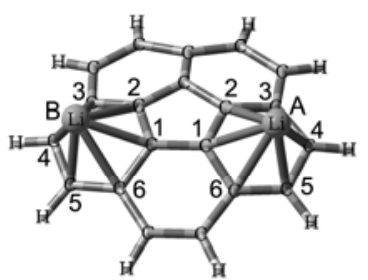

2b

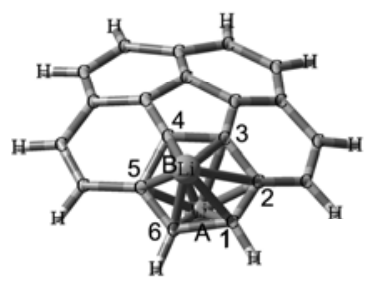

$2 \mathrm{e}$

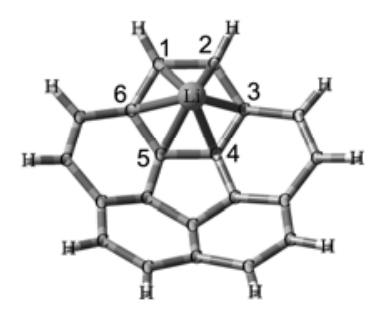

$1 b$

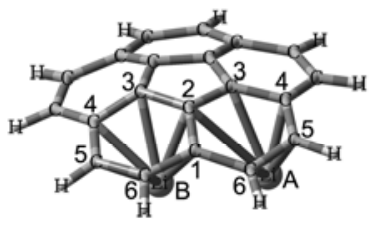

2c

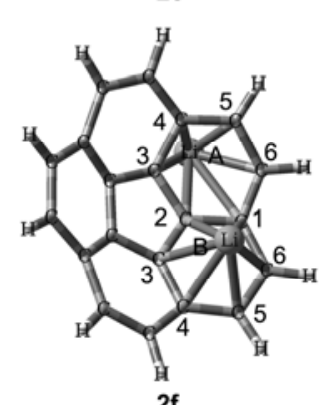

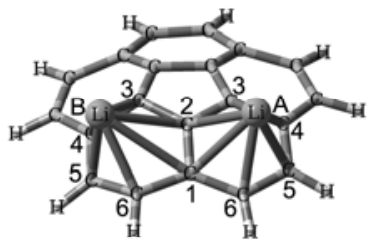

$2 a$

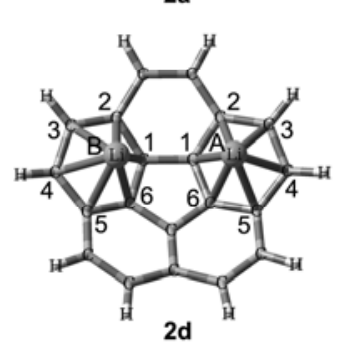

2d

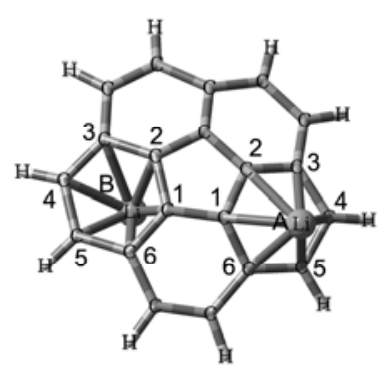

$2 \mathrm{~g}$

Figure 2 Optimized geometries of $\mathrm{Li}_{n}-\mathrm{C}_{20} \mathrm{H}_{10}(n=1,2)$.

Table 1 Selected optimized geometrical parameters $(\AA)$, NBO charges on $\mathrm{Li}$ atoms, and binding energies $\left(E_{\mathrm{b}}, \mathrm{kJ} / \mathrm{mol}\right)$ for $\mathrm{Li}_{n}-\mathrm{C}_{20} \mathrm{H}_{10}(n=1,2)$ complexes $^{\mathrm{a})}$

\begin{tabular}{|c|c|c|c|c|c|c|c|c|}
\hline & $\mathrm{C} 1-\mathrm{Li}$ & $\mathrm{C} 2-\mathrm{Li}$ & C3-Li & $\mathrm{C} 4-\mathrm{Li}$ & C5-Li & C6-Li & $q(\mathrm{Li})^{\mathrm{b})}$ & $E_{\mathrm{b}}(\mathrm{kJ} / \mathrm{mol})^{\mathrm{c})}$ \\
\hline $1 \mathbf{a}$ & 2.288 & 2.211 & 2.315 & 2.434 & 2.158 & 2.140 & 0.918 & -69.7 \\
\hline $1 b$ & 2.178 & 2.185 & 2.221 & 2.253 & 2.244 & 2.206 & 0.942 & -74.1 \\
\hline \multirow[t]{2}{*}{$2 a$} & 2.370 & 2.279 & 2.229 & 2.267 & 2.121 & 2.163 & 0.851 & -162.0 \\
\hline & 2.802 & 2.650 & 2.211 & 2.138 & 2.081 & 2.201 & & \\
\hline \multirow[t]{2}{*}{$2 b$} & 2.204 & 2.442 & 2.519 & 2.143 & 2.110 & 2.220 & 0.882 & -163.8 \\
\hline & 2.204 & 2.443 & 2.520 & 2.143 & 2.110 & 2.220 & & \\
\hline \multirow[t]{2}{*}{$2 c$} & 2.969 & 3.004 & 2.516 & 2.129 & 2.076 & 2.349 & 0.608 & -139.3 \\
\hline & 2.185 & 2.296 & 2.401 & 2.333 & 2.247 & 2.217 & & \\
\hline \multirow[t]{2}{*}{$2 d$} & 2.572 & 2.444 & 2.240 & 2.156 & 2.173 & 2.337 & 0.643 & -152.2 \\
\hline & 2.573 & 2.444 & 2.240 & 2.156 & 2.174 & 2.338 & & \\
\hline \multirow[t]{2}{*}{$2 e$} & 2.150 & 2.789 & 2.667 & 2.216 & 2.179 & 2.114 & 0.862 & -169.4 \\
\hline & 2.377 & 2.132 & 2.191 & 2.456 & 2.246 & 2.162 & & \\
\hline \multirow[t]{2}{*}{$2 f$} & 2.744 & 2.593 & 2.199 & 2.170 & 2.105 & 2.180 & 0.881 & -178.2 \\
\hline & 2.350 & 2.332 & 2.201 & 2.162 & 2.142 & 2.177 & & \\
\hline \multirow[t]{2}{*}{$2 \mathrm{~g}$} & 2.185 & 2.514 & 2.655 & 2.181 & 2.113 & 2.178 & 0.897 & -172.5 \\
\hline & 2.319 & 2.204 & 2.181 & 2.165 & 2.171 & 2.251 & & \\
\hline
\end{tabular}

a) The data for $\mathrm{Li}_{2}-\mathrm{C}_{20} \mathrm{H}_{10}$ consist of two types (from structure $\mathbf{2 a}$ to $\mathbf{2 g}$ ). The first row for each structure refers to the "A" type $\mathrm{Li}$ atom and the second row refers to the "B" type $\mathrm{Li}$ atom (see Figure 2). b) The NBO charges of two Li-doped systems are reported as average values. c) $E_{\mathrm{b}}=E\left(\mathrm{Li}_{n}-\mathrm{C}_{20} \mathrm{H}_{10}\right)-$ $\left[n E(\mathrm{Li})+E\left(\mathrm{C}_{20} \mathrm{H}_{10}\right)\right](n=1,2)$. 
Table 2 Static first hyperpolarizability $\left(\beta_{0}\right)$, transition energies $(\Delta E)$, and oscillating strengths $\left(f_{0}\right)$ for $\mathrm{C}_{20} \mathrm{H}_{10}$ and $\mathrm{Li}_{n}-\mathrm{C}_{20} \mathrm{H}_{10}(n=1,2)$ calculated using B3LYP/6-31G(d,p)

\begin{tabular}{|c|c|c|c|c|c|c|c|c|c|c|}
\hline Property & $\mathrm{C}_{20} \mathrm{H}_{10}$ & $1 \mathrm{a}$ & $1 \mathrm{~b}$ & $2 \mathbf{a}$ & $2 \mathbf{b}$ & $2 \mathrm{c}$ & $2 d$ & $2 \mathrm{e}$ & $2 f$ & $2 \mathrm{~g}$ \\
\hline$\beta_{x}(\mathrm{au})$ & -74 & -3145 & -10 & -6742 & 121 & -1517 & 16 & -7521 & -5391 & 8346 \\
\hline$\beta_{y}(\mathrm{au})$ & -4 & -1151 & 194 & -6394 & -6320 & -1879 & -240 & 881 & -1070 & 986 \\
\hline$\beta_{0}(\mathrm{au})$ & 74 & 4547 & 501 & 15314 & 14762 & 5773 & 6154 & 7866 & 6434 & 9746 \\
\hline$f_{0}$ & 0.099 & 0.059 & 0.074 & 0.029 & 0.039 & 0.036 & 0.039 & 0.016 & 0.077 & 0.041 \\
\hline$\Delta E(\mathrm{eV})$ & 6.366 & 2.190 & 5.205 & 0.947 & 1.228 & 2.090 & 2.048 & 1.547 & 1.635 & 1.409 \\
\hline
\end{tabular}

(2f), and $-172.5 \mathrm{~kJ} / \mathrm{mol}(\mathbf{2 g})$, meaning that they are more stable than those geometries with the two $\mathrm{Li}$ atoms lying on the same side. This therefore suggests that repulsion between the two Li atoms may play an important role in determining the stability of Li-doped corannulene. Interestingly, from the computed binding energies (see Table 1), one can see that adding a second $\mathrm{Li}$ atom to the one-Lidoped structures is thermodynamically favorable.

\subsection{Static first hyperpolarizabilities}

The calculated electronic properties of $\mathrm{Li}_{n}-\mathrm{C}_{20} \mathrm{H}_{10}(n=0,1,2)$ are given in Table 2. One can see that the static first hyperpolarizabilities $\left(\beta_{0}\right)$ values of $\mathrm{C}_{20} \mathrm{H}_{10}$ are only 74 au. For the one-doped systems, the $\beta_{0}$ value of $\mathrm{Li}-\mathrm{C}_{20} \mathrm{H}_{10}$ is $4547 \mathrm{au}$ (1a) and 501 au (1b), respectively. In other words, the $\beta_{0}$ value of $\mathbf{1 a}$ is almost 10 times larger than that of $\mathbf{1 b}$, indicating that a dramatic effect on the first hyperpolarizability results from a variation in the $\mathrm{Li}$ atom location. For the twoLi-doped systems, the value of $\beta_{0}$ decreases in the order $15314 \quad(\mathbf{2 a})>14762 \quad(\mathbf{2 b})>9746 \quad(\mathbf{2 g})>7866 \quad(\mathbf{2 e})>6434$ (2f) $>$ $6154(\mathbf{2 d})>5244(\mathbf{2 c})$ au. It is also interesting to compare the $\beta_{0}$ value of $\mathrm{Li}_{2}-\mathrm{C}_{20} \mathrm{H}_{10}$ with other known systems that possess large $\beta_{0}$ values. The range of $\beta_{0}$ values of $\mathrm{Li}_{n}-\mathrm{C}_{20} \mathrm{H}_{10}$ $(n=1,2)$ is from 5244 to $15314 \mathrm{au}$, which is close to that of the Li@calix[4]pyrrole [8] (3385-15682 au). Comparison among our results shows that the $\beta_{0}$ values of two-Li-doped systems are larger than those of the one-Li-doped systems. From Table 2 and Figure 2, we propose that the $\beta_{0}$ value of $\mathrm{Li}_{n}-\mathrm{C}_{20} \mathrm{H}_{10}(n=1,2)$ systems is strongly associated with the concentration and location of the $\mathrm{Li}$.

It is well known that the $\beta_{0}$ value of a $\mathrm{Li}$ atom itself is close to zero; therefore, it begs the question of how does it cause the large $\beta_{0}$ value on $\mathrm{Li}_{n}-\mathrm{C}_{20} \mathrm{H}_{10}(n=1,2)$ ? According to a two-level expression [38], the $\beta_{0}$ value is dependent on three factors: the excitation energy $(\Delta E)$, the oscillator strength $\left(f_{0}\right)$, and the difference in dipole moment $(\Delta \mu)$ between the crucial transition states. In the two-level expression, the third power of the transition energy is inversely proportional to the $\beta_{0}$ value. Therefore, for the $\mathrm{Li}_{n}-\mathrm{C}_{20} \mathrm{H}_{10}$ $(n=1,2)$ systems, the low transition energy is the decisive factor in providing the large $\beta_{0}$ value. In this work, TD-DFT calculations were carried out to obtain the crucial excited states of the $\mathrm{Li}_{n}-\mathrm{C}_{20} \mathrm{H}_{10}(n=1,2)$ systems, with the results listed in Table 2. The ordering of the $\Delta E$ values is 0.947 $\begin{array}{llll}(\mathbf{2 a})<1.228 & (\mathbf{2 b})<1.409 & (\mathbf{2 g})<1.547 \quad(\mathbf{2 e})<1.635 \quad(\mathbf{2 f})<2.048\end{array}$ $(\mathbf{2 d})<2.090(\mathbf{2 c})<2.190(\mathbf{1 a})<5.205(\mathbf{1 b})<6.366\left(\mathrm{C}_{20} \mathrm{H}_{10}\right) \mathrm{eV}$. One finds that the variation in transition energy of $\mathrm{Li}_{n^{-}}$ $\mathrm{C}_{20} \mathrm{H}_{10}(n=0,1,2)$ is related to the corresponding structures. In addition, Table 3 lists the nature of these crucial transitions. Taking $\mathbf{1 a}$ and $\mathbf{1 b}$ as illustrative examples, owing to the different manners of transition between 1a $(\mathrm{HOMO} \rightarrow$ $\mathrm{LUMO}+2)$ and $\mathbf{1 b}(\mathrm{HOMO} \rightarrow \mathrm{LUMO}+9)$, one can find the difference in the $\beta_{0}$ value for these two structures.

\section{Conclusions}

In the present work, we theoretically designed novel organic electrode compounds $\mathrm{Li}_{n}-\mathrm{C}_{20} \mathrm{H}_{10}(n=1,2)$. The computed NBO charges show that the $\mathrm{Li}$ atom is ionized and transfers electrons to corannulene. The $\beta_{0}$ values of $\mathrm{Li}_{n}-\mathrm{C}_{20} \mathrm{H}_{10}(n=1$, 2) are predicted to be significantly large, about 10-200 times greater than for $\mathrm{C}_{20} \mathrm{H}_{10}$. We suggest that $\beta_{0}$ values of $\mathrm{Li}_{n}-\mathrm{C}_{20} \mathrm{H}_{10}(n=1,2)$ systems are strongly dependent on the concentration and location of the Li. As a result, our investigation may direct attention to the design of new electrodes with large NLO responses via the use of lithium metal doping.

Table 3 Nature of transition in $\mathrm{Li}_{n}-\mathrm{C}_{20} \mathrm{H}_{10}(n=1,2)$

\begin{tabular}{cll}
\hline & Transition & $C_{\mathrm{i}}^{\text {a) }}$ \\
\hline $\mathbf{1 a}$ & HOMO $\rightarrow$ LUMO+2 & 0.76 \\
$\mathbf{1 b}$ & HOMO $\rightarrow$ LUMO+9 & 0.74 \\
$\mathbf{2 a}$ & HOMO $\rightarrow$ LUMO & 0.65 \\
$\mathbf{2 b}$ & HOMO $\rightarrow$ LUMO+2 & 0.68 \\
$\mathbf{2 c}$ & HOMO $\rightarrow$ LUMO+2 & 0.67 \\
$\mathbf{2 d}$ & HOMO $\rightarrow$ LUMO+3 & 0.61 \\
$\mathbf{2 e}$ & HOMO $\rightarrow$ LUMO+1 & 0.67 \\
$\mathbf{2 f}$ & HOMO $\rightarrow$ LUMO+2 & 0.66 \\
$\mathbf{2 g}$ & HOMO $\rightarrow$ LUMO+2 & 0.66 \\
\hline
\end{tabular}

a) Configuration interaction coefficient. 
This work was supported by the National Natural Science Foundation of China (21063009).

1 Eaton D F. Nonlinear optical materials. Science, 1991, 253: 281-287

2 Cheng W D, Xiang K H, Pandey R, et al. Calculations of linear and nonlinear optical properties of $H$-silsesquioxanes. J Phys Chem B, 2000, 104: 6737-6742

3 Ichida M, Sohda T, Nakamura A. Third-order nonlinear optical properties of $\mathrm{C}_{60} \mathrm{CT}$ complexes with aromatic amines. J Phys Chem B, 2000, 104: 7082-7084

4 Hold K, Pawlowski F, Jørgensen P, et al. Calculation of frequencydependent polarizabilities using the approximate coupled-cluster triples model CC3. J Chem Phys, 2003, 118: 1292-1300

5 Hättig C, Larsen $\mathrm{H}$, Olsen J, et al. The effect of intermolecular interactions on the electric properties of helium and argon. I. Ab initio calculation of the interaction induced polarizability and hyperpolarizability in $\mathrm{He}_{2}$ and $\mathrm{Ar}_{2}$. J Chem Phys, 1999, 111: 10099-10107

6 Horikoshi R, Nambu C, Mochida T. Metal-centered ferrocene clusters from 5-ferrocenylpyrimidine and ferrocenylpyrazine. Inorg Chem, 2003, 42: 6868-6875

7 Long N J, Williams C K. Metal alkynyl $\sigma$ complexes: Synthesis and materials. Angew Chem Int Ed, 2003, 42: 2586-2617

8 Chen W, Li Z R, Wu D, et al. The structure and the large nonlinear optical properties of Li@Calix[4]pyrrole. J Am Chem Soc, 2005, 127: 10977-10981

9 Marder S R, Gorman C B, Meyers F, et al. A unified description of linear and nonlinear polarization in organic polymethine dyes. Science, 1994, 265: 632-635

10 Zyss J, Ledoux I. Nonlinear optics in multipolar media: Theory and experiments. Chem Rev, 1994, 94: 77-105

11 Janjua M R S A, Liu C G, Guan W, et al. Prediction of remarkably large second-order nonlinear optical properties of organoimido-substituted hexamolybdates. J Phys Chem A, 2009, 113: 3576-3587

12 Yang J S, Liau K L, Li C Y, et al. Meta conjugation effect on the torsional motion of aminostilbenes in the photoinduced intramolecular charge-transfer state. J Am Chem Soc, 2007, 129: 13183-13192

13 Lee M J, Piao M, Jeong M Y, et al. Novel azo octupoles with large first hyperpolarizabilities. J Mater Chem, 2003, 13: 1030-1037

14 Lee S H, Park J R, Jeong M Y, et al. First hyperpolarizabilities of 1,3,5-tricyanobenzene derivatives: Origin of larger $\beta$ values for the octupoles than for the dipoles. ChemPhysChem, 2006, 7: 206-212

15 Coe B J, Jones L A, Brunschwig B S, et al. Highly unusual effects of $\pi$-conjugation extension on the molecular linear and quadratic nonlinear optical properties of ruthenium(II) ammine complexes. J Am Chem Soc, 2003, 125: 862-863

16 Coe B J, Foxon S P, Harper E C, et al. Nonlinear optical and related properties of iron(II) pentacyanide complexes with quaternary nitrogen electron acceptor units. Inorg Chem, 2009, 48: 1370-1379

17 Chen W, Li Z R, Wu D. Nonlinear optical properties of alkalides $\mathrm{Li}^{+}$(calix[4]pyrrole) $\mathrm{M}^{-}(\mathrm{M}=\mathrm{Li}, \mathrm{Na}$, and $\mathrm{K})$ : Alkali anion atomic number dependence. J Am Chem Soc, 2006, 128: 1072-1073

18 Wang F F, Li Z R, Wu D, et al. Structures and considerable static first hyperpolarizabilities: New organic alkalides $\left(\mathrm{M}^{+} @ n^{6} \mathrm{adz}\right) \mathrm{M}^{\prime}-$ $\left.\left(\mathrm{M}, \mathrm{M}^{\prime}\right) \mathrm{Li}, \mathrm{Na}, \mathrm{K} ; n=2,3\right)$ with cation inside and anion outside of the cage complexants. J Phys Chem B, 2008, 112: 1090-1094

19 Muhammad S, Xu H L, Liao Y, et al. Quantum mechanical design and structure of the $\mathrm{Li} @ \mathrm{~B}_{10} \mathrm{H}_{14}$ basket with a remarkable enhanced electro-optical response. J Am Chem Soc, 2009, 131: 11833-11840

20 Chen M M, Ma F, Li Z R, et al. Series of metal-nonmetal-metal sandwich compounds: Out-of-plane $\sigma$-aromaticity and electric properties. J Phys Chem A, 2009, 113: 8731-8736

$21 \mathrm{Li} \mathrm{Z} \mathrm{J,} \mathrm{Li} \mathrm{Z} \mathrm{R,} \mathrm{Wang} \mathrm{F} \mathrm{F,} \mathrm{et} \mathrm{al.} \mathrm{A} \mathrm{dependence} \mathrm{on} \mathrm{the} \mathrm{petal} \mathrm{number} \mathrm{of}$ the static and dynamic first hyperpolarizability for electride molecules: Many-petal-shaped Li-doped cyclic polyamines. J Phys Chem A, 2009, 113: 2961-2966

22 Ma F, Li Z R, Xu H L, et al. Lithium salt electride with an excess electron pair-A class of nonlinear optical molecules for extraordinary first hyperpolarizability. J Phys Chem A, 2008, 112: 11462-11467

$23 \mathrm{Xu} \mathrm{H} \mathrm{L,} \mathrm{Li} \mathrm{Z} \mathrm{R,} \mathrm{Wu} \mathrm{D,} \mathrm{et} \mathrm{al.} \mathrm{Lithiation} \mathrm{and} \mathrm{Li-doped} \mathrm{effects} \mathrm{of}$ [5]cyclacene on the static first hyperpolarizability. J Phys Chem C, 2009, 113: 4984-4986

24 Zhou Z J, Liu Z B, Li Z R, et al. Shape effect of graphene quantum dots on enhancing second-order nonlinear optical response and spin multiplicity in $\mathrm{NH}_{2}-\mathrm{GQD}-\mathrm{NO}_{2}$ systems. J Phys Chem C, 2011, 115: 16282-16286

25 Tong J, Li Y, Wu D, et al. Ab initio investigation on a new class of binuclear superalkali cations $\mathrm{M}_{2} \mathrm{Li}_{2 \mathrm{k}+1}{ }^{+}\left(\mathrm{F}_{2} \mathrm{Li}_{3}{ }^{+}, \mathrm{O}_{2} \mathrm{Li}_{5}{ }^{+}, \mathrm{N}_{2} \mathrm{Li}_{7}{ }^{+}\right.$, and $\mathrm{C}_{2} \mathrm{Li}_{9}^{+}$). J Phys Chem A, 2011, 115: 2041-2046

26 Tong J, Li Y, Wu D, et al. Lithium bonding interaction hyperpolarizabilities of various Li-bond dimers. J Phys Chem A, 2010, 114: 5888-5893

27 Barth W E, Lawton R G. Dibenzo[ghi,mno]fluoranthene. J Am Chem Soc, 1966, 88: 380-381

28 Lovas F J, McMahon R J, Grabow J U, et al. Interstellar chemistry: A strategy for detecting polycyclic aromatic hydrocarbons in space. $\mathrm{J}$ Am Chem Soc, 2005, 127: 4345-4349

29 Stein S E, Fahr A. High-temperature stabilities of hydrocarbons. J Phys Chem, 1985, 89: 3714-3725

30 Zoppi L, Martin L, Baldridge K K. Effect of molecular packing on cornnulene-based materials electroluminescence. J Am Chem Soc, 2011, 133: 14002-14009

31 Zhang Y, Scanlon L G, Rottmayer M A, et al. Computational investigation of adsorption of molecular hydrogen on Lithium-doped corannulene. J Phys Chem B, 2006, 110: 22532-22541

32 Carrazana-Garcia J A, Rodriguez-Otero J, Cabaleiro-Lago E M. DFT study of the interaction between alkaline cations and molecular bowls derived from fullerene. J Phys Chem B, 2011, 115: 2774-2782

33 Kandalam A K, Rao B K, Jena P. DFT study of structure and binding energies of Fe-corannulene complex. J Phys Chem A, 2005, 109: 9220-9225

34 Green J R, Dunbar R C. When do molecular bowls encapsulate metal cations. J Phys Chem A, 2011, 115: 4968-4975

35 Ayers T M, Westlake B C, Preda D V, et al. Laser plasma production of metal-corannulene ion-molecule complexes. Organometallics, 2005, 24: 4573-4578

36 Frisch M J, Trucks G W, Schlegel H B, et al. Gaussian 03, Revision-B.03. Gaussian Inc., Pittsburgh PA, 2003

37 Petrukhina M A, Andreini K W, Mack J, et al. X-ray quality geometries of geodesic polyarenes from theoretical calculations: What lebels of theory are reliable? J Org Chem, 2005, 70: 5713-5716

38 Kanis D R, Ratner M A, Marks T. Design and construction of molecular assemblies with large second-order optical nonlinearities. Chem Rev, 1994, 94: 195-242

Open Access This article is distributed under the terms of the Creative Commons Attribution License which permits any use, distribution, and reproduction in any medium, provided the original author(s) and source are credited. 